\title{
PREDICTORS OF TRANSFER TO HOME HEMODIALYSIS AFTER PERITONEAL DIALYSIS COMPLETION
}

\author{
Annie-Claire Nadeau-Fredette, ${ }^{1-3}$ Carmel Hawley, ${ }^{1,2,4}$ Elaine Pascoe, ${ }^{5}$ Christopher T. Chan, ${ }^{6}$ Martine Leblanc, ${ }^{3}$ \\ Philip A. Clayton, ${ }^{1,7}$ Kevan R. Polkinghorne, ${ }^{1,8,9}$ Neil Boudville, ${ }^{1,10}$ and David W. Johnson ${ }^{1,2,4}$
}

Australia and New Zealand Dialysis and Transplant Registry, ${ }_{1}^{1}$ Adelaide, and Department of Nephrology, ${ }^{2}$ University of

Queensland at Princess Alexandra Hospital, Brisbane, Australia; Université de Montreal, ${ }^{3}$ Montreal, Quebec, Canada; Centre for Kidney Disease Research, ${ }^{4}$ Translational Research Institute, and School of Medicine, ${ }^{5}$

University of Queensland, Brisbane, Australia; Toronto General Hospital, ${ }^{6}$ University Health Network,

University of Toronto, Toronto, Ontario, Canada; Sydney Medical School, ${ }^{7}$ University of Sydney,

Sydney; Department of Nephrology, ${ }^{8}$ Monash Medical Centre Monash Health, Clayton;

Department of Medicine and of Epidemiology and Preventive Medicine, ${ }^{9}$ Monash

University, Melbourne; and School of Medicine and Pharmacology, ${ }^{10}$

University of Western Australia, Perth, Australia

- Background: The aim of the present study was to evaluate the predictors of transfer to home hemodialysis (HHD) after peritoneal dialysis (PD) completion.

- Methods: All Australian and New Zealand patients treated with PD on day 90 after initiation of renal replacement therapy between 2000 and 2012 were included. Completion of PD was defined by death, transplantation, or hemodialysis (HD) for 180 days or more. Patients were categorized as "transferred to HHD" if they initiated HHD fewer than 180 days after PD had ended. Multivariable logistic regression was used to evaluate predictors of transfer to HHD in a restricted cohort experiencing PD technique failure; a competingrisks analysis was used in the unrestricted cohort.

- Results: Of 10710 incident PD patients, 3752 died, 1549 underwent transplantation, and 2915 transferred to HD, among whom $156(5.4 \%)$ started HHD. The positive predictors of transfer to HHD in the restricted cohort were male sex [odds ratio (OR): 2.81], obesity (OR: 2.20), and PD therapy duration (OR: 1.10 per year). Negative predictors included age (OR: 0.95 per year), infectious cause of technique failure (OR: 0.48), underweight (OR: 0.50), kidney disease resulting from hypertension (OR: 0.38 ) or diabetes (OR: 0.32 ), race being Maori (OR: 0.65 ) or Aboriginal and Torres Strait Islander (OR: 0.30). Comparable results were obtained with a competing-risks model.

- Conclusions: Transfer to HHD after completion of PD is rare and predicted by patient characteristics at baseline and at the time of PD end. Transition to HHD should be considered more often in patients using PD, especially when they fulfill the identified characteristics.

Perit Dial Int 2016; 36(5):547-554 epub ahead of print: 02 Nov 2015 http://dx.doi.org/10.3747/pdi.2015.00121

Correspondence to: D. Johnson, Department of Nephrology, Level 2, Ambulatory Renal and Transplant Services (ARTS) Building, Princess Alexandra Hospital, 199 Ipswich Road, Woolloongabba, Brisbane, Queensland 4102 Australia.

david.johnson2@health.qld.gov.au

Received 18 May 2015; accepted 09 August 2015
KEY WORDS: Home hemodialysis; technique failure; dialysis transition; ANZDATA.

Deritoneal dialysis (PD) is increasingly recognized as a firstchoice modality of renal replacement therapy (RRT) (1-4), especially during the early years, where, compared with facility hemodialysis (HD), it might be associated with a small survival benefit (5-7). However, continuation of PD beyond the first few years is frequently limited by PD technique failure, with recent registry studies reporting a $20 \% \mathrm{HD}$ transfer rate during the first year after PD initiation $(8,9)$. Technique failure during PD has been inconsistently associated with older age, demographic characteristics (race, female sex), diabetes, body mass index (BMI), membrane transport status, and poor ultrafiltration, although the overall predictive capacity of those variables is poor (9-16). Given the relatively short technique survival with PD and the lack of a readily identifiable additional preventive strategy to target, forward planning and optimization of dialysis therapy once patients have completed PD therapy is of paramount importance.

Various groups have recently advocated the use of HHD after PD completion as an opportunity to improve patient care and increase home dialysis uptake (17-19). Small studies have indeed shown the feasibility of such a transition $(17,20,21)$ and have reported good clinical outcomes once HHD is initiated (18). Although the assumption is that only a small number of patients treated with PD could potentially be HHD candidates, the predictors of a transfer to HHD after PD completion remain largely uncertain. Assessment of such predictors appears critical so that patients more likely to transit to HHD can be identified and so that continuation of home dialysis can be encouraged.

The primary objective of the present study was therefore to identify the predictors of transfer to HHD after PD completion.

This single copy is for your personal, non-commercial use only. 
The secondary objective was to ascertain the predictors of how much time patients would require to make the transition from facility HD to HHD after PD completion.

\section{METHODS}

\section{POPULATION AND DATA COLLECTION}

Our study included all patients from Australia and New Zealand treated with PD on day 90 after RRT initiation between 1 January 2000 and 31 December 2012. Data were accessed through the Australia and New Zealand Dialysis and Transplant (ANZDATA) registry, which includes prospectively collected data from all dialysis centers across those two countries. Patients were excluded if they had been on RRT for fewer than 90 days or if they were less than 18 years of age at dialysis start. Completion of PD was defined as death, transplantation, or PD technique failure with 180 or more consecutive days on HD.

\section{OUTCOME DEFINITIONS}

The primary outcome was transfer to HHD after PD completion. Transfer to HHD was defined as initiation of HHD fewer than 180 days after PD end (date of the first day of HD treatment). The predictors of transfer to HHD were evaluated in two models based on different populations. The first model used a restricted cohort consisting only of patients experiencing PD completion after technique failure; patients who died, who underwent kidney transplantation, who recovered kidney function, who were lost to follow-up, or who were still receiving PD or were within 180 days of PD cessation at the end of the study period were excluded. Second, the predictors of transfer to HHD were evaluated in an unrestricted cohort consisting of all patients being treated with PD on day 90 after RRT start.

The secondary outcome was the time spent on facility HD during the transition between PD and HHD for an extended cohort of patients transferring to HHD less than 1 year after PD completion. The transition time was calculated from the first day of facility HD to the first day of HHD and then categorized as less than 90 days, 90-180 days, or 181-365 days.

\section{COVARIATES AND POTENTIAL PREDICTORS}

Baseline characteristics were evaluated at the time of RRT initiation. They included age, sex, race, primary kidney disease, BMI, diabetes mellitus (types 1 and 2), coronary disease, peripheral vascular disease, cerebrovascular disease, pulmonary disease, active smoking, late nephrology referral (<3 months before RRT initiation), era (2000-2005 vs. 20062012), and country (Australia or New Zealand). In patients whose PD completion was a result of technique failure, the duration of PD treatment was calculated from day 90 after RRT initiation (inclusion criterion) to the first day of permanent HD treatment. Causes of transfer to HD were also documented by each dialysis center and submitted to the ANZDATA registry at the time of PD end. Temporary facility HD time was calculated from the first day of facility HD (at the time of PD end) to HHD initiation.

\section{STATISTICAL ANALYSIS}

Predictors of HHD Transfer After PD Technique FailureRestricted Cohort: Predictors of transfer to HHD (compared with facility HD only) after PD completion were first evaluated in unadjusted and multivariable adjusted logistic regression models. Because of differences in the prevalence of and access to HHD across states, standard errors were clustered for the state of initial residence. The adjusted model included the following prespecified variables, based on biologic plausibility, clinical relevance, and previous publications $(9,17)$ : age, sex, race [categorized as white or other, Asian, Australian Aboriginal and Torres Strait Islander (ATSI), Maori, and Pacific Islander], primary kidney disease (categorized as glomerulonephritis, diabetes, hypertension, and other), diabetes, cardiovascular disease (defined as any of coronary, peripheral vascular, or cerebrovascular disease), BMI, country, infectious cause of PD technique failure (vs. noninfectious), and time on PD. Prespecified two-way interactions between all pairs of variables (age, race, sex, diabetes, and cause of PD completion) were evaluated using a likelihood ratio test, with $p<0.05$ being considered significant. The calibration and discrimination of the final model were assessed through goodness-of-fit and C statistic respectively.

\section{SENSITIVITY ANALYSES}

Predictors of a transfer to HHD were evaluated in two sensitivity models based on various definitions of PD completion and transition time between PD end and HHD initiation. First, the definition of PD completion was changed to 30 days or more of HD (compared with 180 days in the main model), while keeping the same allowed transition time ( $<180$ days). Second, the transition time between PD ending and HHD initiation was increased to less than 365 days of facility HD (compared with $<180$ days in main model), while keeping the definition of PD completion unchanged (180 days of HD).

Predictors of Transfer to HHD After PD Start-Unrestricted Cohort: The primary outcome was also assessed in a competing-risks survival model, with transfer to HHD being the "failure" event and transfer to facility HD, death, or transplantation being the competing events. The prespecified covariates already described were included in this model, with the exception of infectious causes of PD technique failure and time on PD, which could not be included in the survival analysis. Standard strategies to visually assess the proportional hazards assumption using graphs and Schoenfeld residuals were applied.

Predictors of Length of Time on Temporary Facility HD: Unadjusted and adjusted ordinal logistic regression models, with standard errors clustered for state of initial 
residence, were used to identify predictors of a longer facility HD transition time. The multivariable adjusted model included prespecified variables (age, sex, race, diabetes, and cause of PD completion) and all variables with a $p$ value less than 0.05 in the unadjusted ordinal logistic regression models (primary kidney disease and country). For the purpose of this analysis, race was recategorized as white, Asian, or indigenous and other. Two-way interactions were evaluated between all pairs of these covariates: age, sex, race, diabetes, and cause of PD completion. The proportional odds assumption was assessed in a likelihood ratio test.

Statistical analyses were performed using the Stata/IC software application (version 12.1: StataCorp, College Station, TX, USA). A two-tailed $p$ value less than 0.05 was considered statistically significant.

\section{RESULTS}

\section{POPULATION CHARACTERISTICS}

Figure 1 depicts the flow algorithm for including patients in the study. Of the 10710 patients who were treated with PD on day 90 after RRT initiation, 2915 (27\%) experienced PD completion because of technique failure during the study period, among whom 156 (5.4\%) were transferred to HHD within 180 days of PD cessation. The remaining 2759 (94.6\%) were classified as permanently transferred to facility HD. Furthermore, 1549 patients completed PD at time of kidney transplantation, and 3752 patients, at the time of death. Table 1 presents the characteristics of the PD patients in the overall cohort.

Inadequate dialysis (related mostly to inadequate solute clearance) was the most frequent cause of PD technique failure among patients transferred to HHD $(n=76,49 \%)$; infection (mostly peritonitis) was the most frequent cause among patients who moved to facility HD ( $n=1362,49 \%)$. Mechanical complications and other cause of technique failure were evenly distributed in the two groups. Table 2 lists detailed causes of PD completion after PD technique failure. For patients transferred

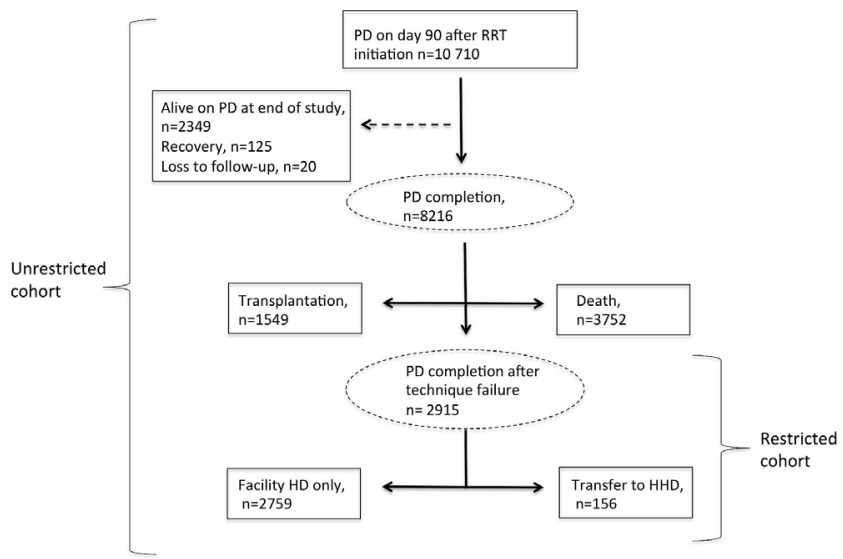

Figure 1 - Patient flow during the study. $\mathrm{PD}=$ peritoneal dialysis; $\mathrm{RRT}=$ renal replacement therapy; $\mathrm{HD}=$ hemodialysis; $\mathrm{HHD}=$ home hemodialysis. to HHD within 180 days of PD completion, the median duration of temporary facility HD was 84 days (interquartile range: 55-127 days).

\section{PREDICTORS OF TRANSFER TO HHD-RESTRICTED COHORT}

In the multivariable logistic regression model, positive predictors of transfer to HHD included male sex, noninfectious causes of PD technique failure, obesity (BMI $\geq 30 \mathrm{~kg} /$ $\mathrm{m}^{2}$ ), and longer duration of PD therapy. In contrast, older age, underweight (BMI $<20 \mathrm{~kg} / \mathrm{m}^{2}$ ), indigenous race (both ATSI and Maori), and a diabetic or hypertensive cause of kidney disease (compared with glomerulonephritis) were negative predictors of transfer to HHD. The final model had

TABLE 1

Baseline Characteristics of the Study Cohort

\begin{tabular}{|c|c|}
\hline Characteristic & Value \\
\hline Patients $(n)$ & 10710 \\
\hline \multicolumn{2}{|l|}{ Age at start of RRT (years) } \\
\hline Median & 62 \\
\hline Interquartile range & $50-71$ \\
\hline $\operatorname{Sex}[n(\%) \operatorname{men}]$ & $6082(57)$ \\
\hline \multicolumn{2}{|l|}{ Race } \\
\hline White & $7389(69)$ \\
\hline Asian & $1236(12)$ \\
\hline ATSI & $601(6)$ \\
\hline Maori & $89(8)$ \\
\hline Pacific Islander & $468(4)$ \\
\hline Other & $117(1)$ \\
\hline \multicolumn{2}{|l|}{ Primary kidney disease $[n(\%)]$} \\
\hline Diabetes & $3739(35)$ \\
\hline Glomerulonephritis & $2662(25)$ \\
\hline Hypertension & $1526(14)$ \\
\hline Polycystic kidney disease & $593(5)$ \\
\hline Reflux & $338(3)$ \\
\hline Other & $1852(17)$ \\
\hline Active smoker at entry $[n(\%)]$ & $1458(14)$ \\
\hline \multicolumn{2}{|l|}{ Comorbidities $[n(\%)]$} \\
\hline Diabetes & $4648(43)$ \\
\hline Coronary disease & $4060(38)$ \\
\hline Peripheral vascular disease & $2585(24)$ \\
\hline Cerebrovascular disease & $1594(15)$ \\
\hline Pulmonary disease & $1606(15)$ \\
\hline \multicolumn{2}{|l|}{ Body mass index $[n(\%)]$} \\
\hline$<20 \mathrm{~kg} / \mathrm{m}^{2}$ & $823(8)$ \\
\hline $20-24 \mathrm{~kg} / \mathrm{m}^{2}$ & $3451(32)$ \\
\hline $25-29 \mathrm{~kg} / \mathrm{m}^{2}$ & $3712(35)$ \\
\hline$\geq 30 \mathrm{~kg} / \mathrm{m}^{2}$ & $2682(25)$ \\
\hline Late nephrology referral $[n(\%)]$ & $2128(20)$ \\
\hline \multicolumn{2}{|l|}{$\operatorname{Era}[n(\%)]$} \\
\hline $2000-2005$ & $4865(45)$ \\
\hline $2006-2012$ & $5845(55)$ \\
\hline New Zealand patients $[n(\%)]$ & $2620(24)$ \\
\hline
\end{tabular}

$\mathrm{RRT}=$ renal replacement therapy; ATSI = Aboriginal and Torres Strait Islander; NZ, New Zealand; PD, peritoneal dialysis.

This single copy is for your personal, non-commercial use only. 
TABLE 2

Causes of Peritoneal Dialysis (PD) Technique Failure in Patients Transferred to Home Hemodialysis (HHD) and Facility Hemodialysis (HD) Only

\begin{tabular}{|c|c|c|}
\hline \multirow[b]{2}{*}{ Causes of PD technique failure } & \multicolumn{2}{|c|}{ Patient group } \\
\hline & $\begin{array}{c}\text { HHD } \\
\text { transfer } \\
(n=156)\end{array}$ & $\begin{array}{l}\text { Facility } \\
\text { HD only } \\
(n=2759)\end{array}$ \\
\hline \multicolumn{3}{|l|}{ Infections $[n(\%)]$} \\
\hline Peritonitis & $39(25)$ & $1229(45)$ \\
\hline Tunnel or exit-site infection & $3(2)$ & $96(3)$ \\
\hline Other abdominal infection & 0 & $37(1)$ \\
\hline Total & $42(27)$ & $1362(49)$ \\
\hline \multicolumn{3}{|l|}{ Inadequate dialysis $[n(\%)]$} \\
\hline Inadequate solute clearance & $61(39)$ & $384(14)$ \\
\hline Inadequate ultrafiltration & $15(10)$ & $147(5)$ \\
\hline Total & $76(49)$ & $531(19)$ \\
\hline \multicolumn{3}{|l|}{ Mechanical complications $[n(\%)]$} \\
\hline Dialysate leak & $7(4)$ & $162(6)$ \\
\hline Catheter-related problems & $1(<1)$ & $78(3)$ \\
\hline Other mechanical problems & $11(7)$ & $113(4)$ \\
\hline Total & $19(12)$ & $353(13)$ \\
\hline \multicolumn{3}{|l|}{ Other $[n(\%)]$} \\
\hline Abdominal or other surgery & $4(3)$ & $113(4)$ \\
\hline Patient choice & $9(6)$ & $128(5)$ \\
\hline Inability to manage self-care & 0 & $179(6)$ \\
\hline Other or unknown & $6(4)$ & $93(3)$ \\
\hline Total & $19(12)$ & $513(19)$ \\
\hline
\end{tabular}

good predictive capacity (C statistic: 0.82 ) and appropriate calibration. No significant effects were evident among the prespecified interaction terms. Table 3 presents detailed results from the multivariable adjusted logistic regression model.

Sensitivity Analyses: When the definition of PD technique failure was changed to 30 days of HD (instead of 180 days), 3955 patients were categorized as reaching PD completion, among whom 153 (3.9\%) were transferred to HHD fewer than 180 days after PD end. In a second sensitivity model, a longer transition-time allowance (<365 days) between PD end and HHD initiation (while keeping the same 180-day definition for PD technique failure) increased the number of patients transferred to HHD to $272(9.3 \%)$. In both sensitivity models, predictors of transfer to HHD after PD completion were globally similar to those identified in the main model (Table 4). Notably, treatment in New Zealand (compared with Australia) was associated with an increase by a factor of 2 in the odds of transfer to HHD when the allowance for the transition time between PD completion and HHD initiation was increased to 365 days.

\section{PREDICTORS OF TRANSFER TO HHD AFTER PD START- UNRESTRICTED COHORT}

The competing-risks model included all 10710 patients treated with PD on day 90 after RRT initiation. Of those patients,
2759 were transferred to facility HD, 3752 died, and 1549 underwent renal transplantation. With the exception of Pacific Islander race, other positive predictors of time to HHD transfer $(n=156)$ were similar to those emerging from the logistic regression model: male sex and overweight or obesity. Similarly, older age, diabetes or hypertensive disease as a cause of renal failure (compared with glomerulonephritis), and cardiovascular disease were all associated with lower odds of transfer to HHD after PD initiation (Table 3).

\section{PREDICTORS OF LENGTH OF TRANSITION TIME}

Based on the sensitivity model showing similar predictors of transfer to HHD after PD technique failure whether using a 180or 365-day maximum transition time, the secondary outcome of transition time length included all 272 patients who initiated HHD less than 1 year after PD completion. Figure 2 shows the distribution of transition durations for those patients. When transition duration was categorized, 87 patients $(32 \%)$ had a facility HD transition duration shorter than 90 days, 71 patients (26\%) remained on temporary facility HD for 90-180 days, and 114 patients $(42 \%)$ had a facility HD transition duration of 181-365 days. Table 5 presents predictors of transition duration based on multivariable ordinal logistic regression. Older age, infectious cause of PD end, and treatment in New Zealand (compared with Australia) were associated with a longer transition time. Male sex and Asian race (compared with white race) were associated with a shorter transition time.

\section{DISCUSSION}

In this registry study, only $5 \%$ of all patients experiencing PD completion after PD technique failure were transferred to HHD in fewer than 180 days after PD ended. The positive predictors of such a transfer included male sex, obesity, and longer duration of PD therapy. In contrast, older age, diabetic or hypertensive kidney disease (compared with glomerulonephritis), cardiovascular disease, infectious causes of PD end, and Australian and New Zealand indigenous racial origin were associated with lower odds of transfer to HHD. In a competing-risks model assessing the unrestricted cohort, male sex, Pacific Islander race, and overweight or obesity were associated with a higher sub-hazard ratio for transfer to HHD; older age, diabetic or hypertensive kidney disease (compared with glomerulonephritis), and cardiovascular disease were associated with a lower sub-hazard ratio for transfer to $H H D$. Furthermore, a longer transition duration in facility HD between PD completion and HHD initiation was predicted by older age, infectious cause of PD end, treatment in New Zealand, and female sex.

In the present study, use of the term "PD completion" was elected instead of the more classical "PD technique failure" to reflect the long duration of $\mathrm{HD}$ treatment required for inclusion in that category. The 180-day HD duration was specifically selected to exclude patients temporarily switched to HD who eventually switched back to PD. 
TABLE 3

Predictors of Transition to Home Hemodialysis in the Restricted and Unrestricted Cohorts

\begin{tabular}{|c|c|c|c|c|c|c|}
\hline \multirow[b]{2}{*}{ Covariate } & \multicolumn{3}{|c|}{$\begin{array}{l}\text { Restricted cohort }{ }^{\mathrm{a}} \\
(n=2915) \\
\text { Multivariable logistic regression }\end{array}$} & \multicolumn{3}{|c|}{$\begin{array}{l}\text { Unrestricted cohort } \\
\quad(n=10710) \\
\text { Competing-risk survival analysis }\end{array}$} \\
\hline & OR & $95 \%$ CI & $p$ Value & SHR & $95 \%$ CI & $p$ Value \\
\hline Age, per year & 0.95 & 0.94 to 0.97 & $<0.001$ & 0.95 & 0.95 to 0.96 & $<0.001$ \\
\hline Male sex & 2.81 & 2.19 to 3.60 & $<0.001$ & 2.85 & 2.30 to 3.54 & $<0.001$ \\
\hline \multicolumn{7}{|l|}{ Race } \\
\hline White and other & & Reference & & & Reference & \\
\hline Asian & 2.12 & $0.85-5.26$ & 0.11 & 1.97 & 0.86 to 4.52 & 0.11 \\
\hline ATSI & 0.30 & $0.13-0.65$ & 0.002 & 0.49 & 0.21 to 1.16 & 0.11 \\
\hline Maori & 0.65 & $0.50-0.85$ & 0.002 & 1.04 & 0.84 to 1.30 & 0.70 \\
\hline Pacific Islanders & 1.49 & $0.92-2.40$ & 0.10 & 2.11 & 1.48 to 3.00 & $<0.001$ \\
\hline \multicolumn{7}{|l|}{ Primary kidney disease } \\
\hline Glomerulonephritis & & Reference & & & Reference & \\
\hline Diabetes & 0.32 & $0.16-0.64$ & 0.001 & 0.30 & 0.16 to 0.59 & $<0.001$ \\
\hline Hypertension & 0.38 & $0.19-0.74$ & 0.005 & 0.36 & 0.17 to 0.73 & 0.005 \\
\hline Other & 1.04 & $0.64-1.72$ & 0.84 & 0.99 & 0.63 to 1.58 & 0.97 \\
\hline Diabetes & 0.93 & 0.48 to 1.83 & 0.86 & 0.93 & $0.50-1.75$ & 0.83 \\
\hline Cardiovascular disease $\mathrm{b}^{\mathrm{b}}$ & 0.79 & 0.63 to 0.99 & 0.04 & 0.74 & $0.60-0.91$ & 0.004 \\
\hline \multicolumn{7}{|l|}{ Body mass index } \\
\hline$<20 \mathrm{~kg} / \mathrm{m}^{2}$ & 0.50 & $0.28-0.88$ & 0.01 & 0.50 & 0.27 to 0.92 & 0.03 \\
\hline $20-24.9 \mathrm{~kg} / \mathrm{m}^{2}$ & & Reference & & & Reference & \\
\hline $25-29.9 \mathrm{~kg} / \mathrm{m}^{2}$ & 1.44 & $0.93-2.21$ & 0.10 & 1.44 & 1.02 to 2.01 & 0.04 \\
\hline$\geq 30 \mathrm{~kg} / \mathrm{m}^{2}$ & 2.20 & $1.31-4.00$ & 0.004 & 2.94 & 1.77 to 4.88 & $<0.001$ \\
\hline New Zealand (vs. Australian) patient & 1.22 & 0.78 to 1.92 & 0.38 & 0.94 & $0.68-1.29$ & 0.69 \\
\hline $\begin{array}{l}\text { Infectious (vs. noninfectious) cause } \\
\text { of technique failure }\end{array}$ & 0.48 & 0.34 to 0.69 & $<0.001$ & - & - & - \\
\hline Duration of PD, per year & 1.10 & 1.01 to 1.20 & 0.04 & - & - & - \\
\hline
\end{tabular}

$\mathrm{OR}=$ odd ratio; $\mathrm{CI}=$ confidence interval; $\mathrm{SHR}=$ sub-hazard ratio; $\mathrm{ATSI}=$ Aboriginal and Torres Strait Islander; PD = peritoneal dialysis.

a Restricted cohort of patients with PD completion due to technique failure with transfer to hemodialysis

${ }^{b}$ Any of coronary, peripheral vascular, or cerebrovascular disease.

Despite the high probability of PD end (or technique failure) in the journey of PD therapy, knowledge about this transition period remains limited. Many studies have attempted to identify predictors of PD technique failure (and transfer to HD), with somewhat inconsistent results and overall poor predictive capacity (9-15).

Although the use of HHD after PD completion could be seen as an optimal scenario in many countries promoting home dialysis, very few data about this specific transition are available. A Canadian single-center study reported the outcomes in 85 patients with PD technique failure, among whom $12(16 \%)$ were transferred to HHD and the other 63 to facility HD (17). That HHD transfer rate represented a much higher rate than the Canadian national average rate of $1 \%$ (as stated by the authors). In unadjusted analyses, patients transferred to HHD were younger and were less likely to have an infection-related causes of PD technique failure. Other publications assessing HHD after PD completion have been mostly descriptive, without direct comparisons to patients transferred to facility HD $(20,22)$.

In the present study, predictors of transfer to HHD were somewhat similar to the baseline characteristics of patients included in incident HHD cohorts (23-28). Indeed, older age was associated with a lower chance of transfer to HHD, which is in keeping with the young age of most HHD cohorts $(25,26,28)$. Similarly, patients with nondiabetic kidney disease had a higher chance of transfer to HHD, which also accords with the HHD literature-in which, for instance, diabetes is associated with a higher risk of HHD training failure (29).

Although not explored in this study, complications related to aging and diabetes, such as decreased sight and dexterity, could be associated with both PD failure and inability to transfer to HHD. Australian (ATSI) and New Zealand (Maori) indigenous patients were also less likely to transfer to HHD during the first 180 days after PD completion $(24,25)$. Finally, men were twice as likely to switch to HHD and to experience shorter transition times, which might be related to easier arteriovenous fistula creation in men (30-32) and, perhaps, a more traditional caregiver role for female spouses $(33,34)$.

Nevertheless, the present study also identified predictors more closely related to PD therapy. Patients with an infectious cause of PD end had a lower chance of transfer to HHD and, when such a transfer occurred, the transition took longer, which might reflect the acuteness of the end to their PD course.

This single copy is for your personal, non-commercial use only.

For permission to reprint multiple copies or to order presentation-ready

copies for distribution, contact Multimed Inc. at marketing@multi-med.com 
TABLE 4

Multivariable Adjusted Predictors of Transfer to Home Hemodialysis in the Restricted Cohort, Sensitivity Models

\begin{tabular}{|c|c|c|c|c|c|c|}
\hline \multirow[b]{2}{*}{ Covariate } & \multicolumn{3}{|c|}{$\begin{array}{l}\text { Sensitivity model } 1^{\text {a }} \\
\text { 30-Day PD technique failure } \\
\text { 180-Day transition period }\end{array}$} & \multicolumn{3}{|c|}{$\begin{array}{l}\text { Sensitivity model } 2^{\mathrm{a}} \\
\text { 180-Day PD technique failure } \\
\text { 365-Day transition period }\end{array}$} \\
\hline & OR & $95 \% \mathrm{CI}$ & $p$ Value & OR & $95 \% \mathrm{CI}$ & $p$ Value \\
\hline Age, per year & 0.95 & 0.94 to 0.97 & $<0.001$ & 0.96 & 0.94 to 0.98 & $<0.001$ \\
\hline Male sex & 2.90 & 2.17 to 3.87 & $<0.001$ & 1.84 & 1.58 to 2.14 & $<0.001$ \\
\hline \multicolumn{7}{|l|}{ Race } \\
\hline White and other & & Reference & & & Reference & \\
\hline Asian & 2.21 & 1.18 to 4.15 & 0.01 & 1.37 & 0.55 to 3.41 & 0.49 \\
\hline ATSI & 0.25 & 0.12 to 0.51 & $<0.001$ & 0.56 & 0.24 to 1.32 & 0.19 \\
\hline Maori & 0.89 & 0.64 to 1.20 & 0.49 & 0.70 & 0.56 to 0.88 & 0.003 \\
\hline Pacific Islander & 1.57 & 1158 to 2.15 & 0.005 & 1.34 & 1.04 to 1.72 & 0.02 \\
\hline \multicolumn{7}{|l|}{ Primary kidney disease } \\
\hline Glomerulonephritis & & Reference & & & Reference & \\
\hline Diabetes & 0.35 & 0.18 to 0.68 & 0.01 & 0.42 & 0.21 to 0.81 & 0.01 \\
\hline Hypertension & 0.33 & 0.18 to 0.68 & 0.002 & 0.54 & 0.41 to 0.71 & $<0.001$ \\
\hline Other & 1.01 & 0.56 to 1.82 & 0.96 & 0.95 & 0.64 to 1.40 & 0.79 \\
\hline Diabetes & 0.93 & 0.49 to 1.75 & 0.76 & 0.80 & 0.45 to 1.40 & 0.43 \\
\hline Cardiovascular disease $\mathrm{b}^{\mathrm{b}}$ & 0.78 & 0.63 to 0.96 & 0.02 & 0.86 & 0.63 to 1.18 & 0.35 \\
\hline \multicolumn{7}{|l|}{ Body mass index } \\
\hline Less than $20 \mathrm{~kg} / \mathrm{m}^{2}$ & 0.48 & 0.26 to 0.89 & 0.02 & 0.60 & 0.33 to 1.09 & 0.09 \\
\hline $20-24.9 \mathrm{~kg} / \mathrm{m}^{2}$ & & Reference & & & Reference & \\
\hline $25-29.9 \mathrm{~kg} / \mathrm{m}^{2}$ & 1.54 & 0.89 to 2.66 & 0.12 & 1.38 & 1.08 to 1.76 & 0.01 \\
\hline 30 and over $\mathrm{kg} / \mathrm{m}^{2}$ & 2.66 & 1.33 to 5.34 & 0.006 & 1.76 & 1.40 to 2.21 & $<0.001$ \\
\hline New Zealand (vs. Australian) patient & 0.99 & 0.77 to 1.28 & 0.96 & 2.02 & 1.32 to 3.11 & 0.001 \\
\hline $\begin{array}{l}\text { Infectious (vs. noninfectious) cause } \\
\text { of technique failure }\end{array}$ & 0.40 & 0.25 to 0.63 & $<0.001$ & 0.63 & 0.49 to 0.82 & 0.001 \\
\hline Duration of PD, per year & 1.18 & 1.12 to 1.24 & $<0.001$ & 1.04 & 1.00 to 1.09 & 0.04 \\
\hline
\end{tabular}

$\mathrm{PD}=$ peritoneal dialysis; $\mathrm{OR}=$ odds ratio; $\mathrm{CI}=$ confidence interval; $\mathrm{ATSI}=$ Aboriginal and Torres Strait Islander.

${ }^{a}$ C-Statistic: sensitivity model $1=0.83$; sensitivity model $2=0.77$.

${ }^{\mathrm{b}}$ Any of coronary, peripheral vascular, or cerebrovascular disease.

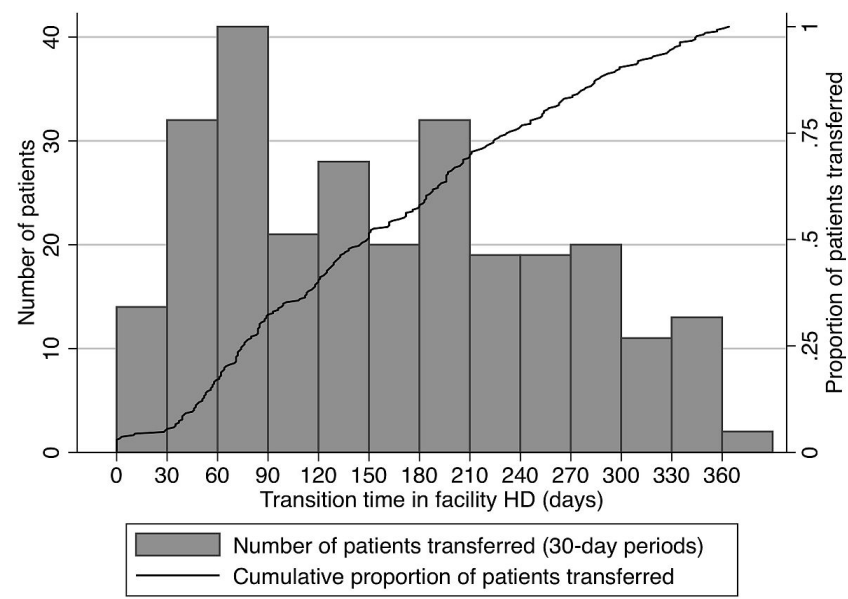

Figure 2 - Time on temporary facility hemodialysis (HD) for patients transferred to home HD during the first year after peritoneal dialysis completion.

In contrast, "insufficient dialysis" was the cause of PD end for almost half the HHD transfer group, which could have potentially allowed time for advance planning for PD completion, creation of an arteriovenous access, and initiation of HHD education $(9,35)$. The positive association between longer duration of PD therapy and transfer to HHD after PD completion could be related to a lower rate of PD complications, perhaps because of greater skill with self-care therapy.

Finally, patients with larger BMI $\left(\geq 30 \mathrm{~kg} / \mathrm{m}^{2}\right)$ in the present study were more likely to transfer to HHD. Because increased BMI has previously been associated with a higher risk for peritonitis $(8,36-38)$ and technique failure $(39,40)$, it is possible that obese patients committed to home dialysis, but after experiencing complications on PD, were more steadily encouraged to transfer to HHD. Likewise, the association between higher BMI and HHD transfer could be related to a need for more intensive dialysis, easily accessible through HHD (41).

It is also important to note the effect of health care system when assessing transition between dialysis modalities. Indeed, in the present study, being treated in New Zealand (compared with Australia) was associated with a longer transition between PD completion and HHD initiation. However, when the modeled transition time was extended to 365 days, patients in New Zealand were twice as likely as Australian patients to be transferred to HHD. Notably, no specific policies addressed 
TABLE 5

Predictors of Longer Facility Hemodialysis Transition Time Before Home Hemodialysis Initiation, Multivariable Ordinal Logistic Regression ${ }^{a}$

\begin{tabular}{|c|c|c|c|}
\hline Covariate & OR & $95 \% \mathrm{CI}$ & $p$ Value \\
\hline Age, per year & 1.02 & 1.00 to 1.03 & $<0.001$ \\
\hline Male sex & 0.53 & 0.34 to 0.83 & 0.006 \\
\hline \multicolumn{4}{|l|}{ Race } \\
\hline White & & Reference & \\
\hline Asian & 0.48 & 0.33 to 0.72 & $<0.001$ \\
\hline Indigenous and other & 0.80 & 0.51 to 1.27 & 0.35 \\
\hline \multicolumn{4}{|l|}{ Primary kidney disease } \\
\hline Glomerulonephritis & & Reference & \\
\hline Hypertension & 2.42 & 0.80 to 7.35 & 0.12 \\
\hline Diabetes & 1.57 & 0.91 to 2.69 & 0.10 \\
\hline Other & 1.04 & 0.59 to 1.84 & 0.90 \\
\hline Diabetes & 0.88 & 0.53 to 1.45 & 0.61 \\
\hline $\begin{array}{l}\text { Infectious (vs. noninfectious) } \\
\text { cause of PD technique failure }\end{array}$ & 2.08 & 1.08 to 4.03 & 0.03 \\
\hline $\begin{array}{l}\text { New Zealand (vs. Australian) } \\
\text { patient }\end{array}$ & 2.55 & 1.50 to 4.34 & 0.001 \\
\hline
\end{tabular}

$\mathrm{OR}=$ odds ratio; $\mathrm{CI}=$ confidence interval; $\mathrm{PD}=$ peritoneal dialysis.

a Level 1 : $<90$ days $(n=87)$; Level 2: $90-180$ days $(n=71)$; Level 3: $181-365$ days $(n=114)$.

transfer to HHD after PD completion in Australia and New Zealand during the study period.

Among our study's strengths is its inclusion of PD patients from all centers across Australia and NewZealand, two countries that are among those having the highest proportion of dialysis patients treated with home dialysis (42). Hence, the present study offers a unique opportunity to describe the transition from PD to HHD and to highlight how infrequent that transition can be, even in home dialysis-oriented countries that have, for instance, the highest proportion of HHD internationally: $18 \%$ in New Zealand and 9\% in Australia compared with only $4 \%$ in Canada and $1 \%$ in the United States. The use of sensitivity models allowing for different definitions of PD completion and maximum transition time between PD end and HHD initiation also strengthens the study results, especially considering the lack of formal definitions in this area. Moreover, evaluation of the primary outcome in a competing-risks survival modelwhich allowed for inclusion of the entire ("unrestricted") PD cohort and took into account PD completion because of death and transplantation-yielded consistent results.

Our study also had several limitations, including the limited depth of registry data collection and a consequent lack of access to other potentially important characteristics such as education level, marital status, and other socioeconomic factors. Because of the nature of the data, identification of anticipated or planned transfers to HHD was impossible. Furthermore, center-specific characteristics that might influence dialysis modality selection were unable to be ascertained. Specific associations between centers or states and transfer from PD to HHD could not be assessed because of statistical power constraints. Finally, the results of the present study might not apply to other countries where jurisdictions or experiences with home dialysis differ.

\section{CONCLUSIONS}

Our study showed that, after PD end because of technique failure, only $5 \%$ of patients experiencing PD completion were transferred to HHD in fewer than 180 days. Positive predictors of transition to HHD included younger age, male sex, obesity, and longer duration of PD therapy. In contrast, Australian and New Zealand indigenous patients, patients with diabetic or hypertensive kidney disease, and patients with infectious causes of PD end were less likely to be transferred to HHD. Further studies should be performed to validate these findings in other populations, to identify patients for which HHD might be associated with the greatest benefits, and most importantly, to identify strategies to increase the frequency of transition between PD and HHD. Such strategies could notably include elective (and planned) transfer to HHD for PD patients with multiple and repetitive PD-related complications, initiation of unplanned $H D$ by specific $H D$ teams performing training with a home dialysis orientation, and integration of PD and HHD into a global home dialysis program to facilitate increased patient exposure to both modalities.

\section{ACKNOWLEDGMENTS}

The authors gratefully acknowledge the substantial contribution of the entire Australia and New Zealand nephrology community (physicians, surgeons, database managers, nurses, renal operators, and patients) in providing information for and maintaining the ANZDATA registry database.

\section{DISCLOSURES}

ACNF is supported by a Baxter Healthcare Clinical Evidence Council research grant and is a current recipient of a Fonds de la recherche du Québec - Santé scholarship. DWJ is a current recipient of a Queensland Government Health Research Fellowship. He has previously received consultancy fees, research grants, speaker's honoraria, and travel sponsorships from Baxter Healthcare and Fresenius Medical Care. CTC holds the R. Fraser Elliott Chair in Home Dialysis. NB has previously received research funds from Roche; travel grants from Roche, Amgen, and Jansen Cilag; and speaking honoraria from Roche. The other authors have no financial disclosures to make.

\section{REFERENCES}

1. Chaudhary K, Sangha H, Khanna R. Peritoneal dialysis first: rationale. Clin J Am Soc Nephrol 2011; 6:447-56.

2. Lameire N, Van Biesen W, Vanholder R. The role of peritoneal dialysis as first modality in an integrative approach to patients with end-stage renal disease. Perit Dial Int 2000; 20(Suppl 2):S134-41.

3. Li PK, Chow KM. Peritoneal dialysis-first policy made successful: perspectives and actions. Am J Kidney Dis 2013; 62:993-1005.

4. Liu FX, Gao X, Inglese G, Chuengsaman P, Pecoits-Filho R, Yu A. A global overview of the impact of peritoneal dialysis first or favored policies: an opinion. Perit Dial Int 2014; 35:406-20.

5. Lukowsky LR, Mehrotra R, Kheifets L, Arah OA, Nissenson AR,

This single copy is for your personal, non-commercial use only.

For permission to reprint multiple copies or to order presentation-ready

copies for distribution, contact Multimed Inc. at marketing@multi-med.com 
Kalantar-Zadeh K. Comparing mortality of peritoneal and hemodialysis patients in the first 2 years of dialysis therapy: a marginal structural model analysis. Clin J Am Soc Nephrol 2013; 8:619-28.

6. McDonald SP, Marshall MR, Johnson DW, Polkinghorne KR. Relationship between dialysis modality and mortality. J Am Soc Nephrol 2009; 20:155-63.

7. Yeates K, Zhu N, Vonesh E, Trpeski L, Blake P, Fenton S. Hemodialysis and peritoneal dialysis are associated with similar outcomes for endstage renal disease treatment in Canada. Nephrol Dial Transplant 2012; 27:3568-75.

8. Pulliam J, Li NC, Maddux F, Hakim R, Finkelstein FO, Lacson EJr. First-year outcomes of incident peritoneal dialysis patients in the United States. Am J Kidney Dis 2014; 64:761-9.

9. Lan PG, Clayton PA, Saunders J, Polkinghorne KR, Snelling PL. Predictors and outcomes of transfers from peritoneal dialysis to hemodialysis. Perit Dial Int 2014; 35:306-15.

10. Brimble KS, Walker M, Margetts PJ, Kundhal KK, Rabbat CG. Meta-analysis: peritoneal membrane transport, mortality, and technique failure in peritoneal dialysis. J Am Soc Nephrol 2006; 17:2591-8.

11. Chidambaram M, Bargman JM, Quinn RR, Austin PC, Hux JE, Laupacis A. Patient and physician predictors of peritoneal dialysis technique failure: a population based, retrospective cohort study. Perit Dial Int 2011; 31:565-73.

12. Jansen MA, Termorshuizen F, Korevaar JC, Dekker FW, Boeschoten E, Krediet RT, on behalf of the NECOSAD Study Group. Predictors of survival in anuric peritoneal dialysis patients. Kidney Int 2005; 68:1199-205.

13. Rumpsfeld M, McDonald SP, Johnson DW. Higher peritoneal transport status is associated with higher mortality and technique failure in the Australian and New Zealand peritoneal dialysis patient populations. J Am Soc Nephrol 2006; 17:271-8.

14. Shen JI, Mitani AA, Saxena AB, Goldstein BA, Winkelmayer WC. Determinants of peritoneal dialysis technique failure in incident us patients. Perit Dial Int 2013; 33:155-66.

15. Jager KJ, Merkus MP, Dekker FW, Boeschoten EW, Tijssen JG, Stevens P, et al. Mortality and technique failure in patients starting chronic peritoneal dialysis: results of the Netherlands Cooperative Study on the Adequacy of Dialysis. NECOSAD Study Group. Kidney Int 1999; 55:1476-85.

16. Pajek J, Hutchison AJ, Bhutani S, Brenchley PE, Hurst H, Perme MP, et al. Outcomes of peritoneal dialysis patients and switching to hemodialysis: a competing risks analysis. Perit Dial Int 2014; 34:289-98.

17. Cina DP, Dacouris N, Kashani M, Unana B, Cook R, Fung J, et al. Use of home hemodialysis after peritoneal dialysis technique failure. Perit Dial Int 2013; 33:96-9.

18. Nadeau-Fredette AC, Bargman JM, Chan CT. Clinical outcome of home hemodialysis in patients with previous peritoneal dialysis exposure: evaluation of the integrated home dialysis model. Perit Dial Int 2014; 35:316-23.

19. Nesrallah G, Mendelssohn DC. Modality options for renal replacement therapy: the integrated care concept revisited. Hemodial Int 2006; 10:143-51.

20. Suzuki H, Hoshi H, Inoue T, Kikuta T, Tsuda M, Takenaka T. New modality of dialysis therapy: peritoneal dialysis first and transition to home hemodialysis. Adv Perit Dial 2012; 28:106-11.

21. Wong B, Zimmerman D, Reintjes F, Courtney M, Klarenbach S, Dowling G, et al. Procedure-related serious adverse events among home hemodialysis patients: a quality assurance perspective. Am J Kidney Dis 2014; 63:251-8.

22. Wong JH, Pierratos A, Oreopoulos DG, Mohammad R, Benjamin-Wong F, Chan CT. The use of nocturnal home hemodialysis as salvage therapy for patients experiencing peritoneal dialysis failure. Perit Dial Int 2007; 27:669-74.

23. Jun M, Jardine MJ, Gray N, Masterson R, Kerr PG, Agar JW, et al. Outcomes of extended-hours hemodialysis performed predominantly at home. Am J Kidney Dis 2013; 61:247-53.

24. Marshall MR, Hawley CM, Kerr PG, Polkinghorne KR, Marshall RJ, Agar JW, et al. Home hemodialysis and mortality risk in Australian and New Zealand populations. Am J Kidney Dis 2011; 58:782-93.

25. Marshall MR, Walker RC, Polkinghorne KR, Lynn KL. Survival on home dialysis in New Zealand. PLoS One 2014; 9:e96847.

26. Nitsch D, Steenkamp R, Tomson CR, Roderick P, Ansell D, MacGregor MS. Outcomes in patients on home haemodialysis in England and Wales, 1997-2005: a comparative cohort analysis. Nephrol Dial Transplant 2011; 26:1670-7.

27. Rioux JP, Bargman JM, Chan CT. Systematic differences among patients initiated on home haemodialysis and peritoneal dialysis: the fallacy of potential competition. Nephrol Dial Transplant 2010; 25:2364-7.

28. Tennankore KK, Kim SJ, Baer HJ, Chan CT. Survival and hospitalization for intensive home hemodialysis compared with kidney transplantation. J Am Soc Nephrol 2014; 25:2113-20.

29. Schachter ME, Tennankore KK, Chan CT. Determinants of training and technique failure in home hemodialysis. Hemodial Int 2013; 17:421-6.

30. Allon M, Ornt DB, Schwab SJ, Rasmussen C, Delmez JA, Greene T, et al. Factors associated with the prevalence of arteriovenous fistulas in hemodialysis patients in the HEMO study. Hemodialysis (HEMO) Study Group. Kidney Int 2000; 58:2178-85.

31. Ethier J, Mendelssohn DC, Elder SJ, Hasegawa T, Akizawa T, Akiba T, et al. Vascular access use and outcomes: an international perspective from the dialysis outcomes and practice patterns study. Nephrol Dial Transplant 2008; 23:3219-26.

32. Pounds LL, Teodorescu VJ. Chronic kidney disease and dialysis access in women. J Vasc Surg 2013; 57(Suppl):49S-53S.e1.

33. Belasco AG, Sesso R. Burden and quality of life of caregivers for hemodialysis patients. Am J Kidney Dis 2002; 39:805-12.

34. Wise M, Schatell D, Klicko K, Burdan A, Showers M. Successful daily home hemodialysis patient-care partner dyads: benefits outweigh burdens. Hemodial Int 2010; 14:278-88.

35. Boissinot L, Landru I, Cardineau E, Zagdoun E, RyckelycnkJP, Lobbedez T. Is transition between peritoneal dialysis and hemodialysis really a gradual process? Perit Dial Int 2013; 33:391-7.

36. Lim WH, Johnson DW, McDonald SP. Higher rate and earlier peritonitis in Aboriginal patients compared to non-Aboriginal patients with end-stage renal failure maintained on peritoneal dialysis in Australia: analysis of ANZDATA. Nephrology (Carlton) 2005; 10:192-7.

37. McDonald SP, Collins JF, Rumpsfeld M, Johnson DW. Obesity is a risk factor for peritonitis in the Australian and New Zealand peritoneal dialysis patient populations. Perit Dial Int 2004; 24:340-6.

38. Prasad N, Sinha A, Gupta A, Sharma RK, Bhadauria D, Chandra A, et al. Effect of body mass index on outcomes of peritoneal dialysis patients in India. Perit Dial Int 2014; 34:399-408.

39. Badve SV, Hawley CM, McDonald SP, Mudge DW, Rosman JB, Brown FG, et al. Automated and continuous ambulatory peritoneal dialysis have similar outcomes. Kidney Int 2008; 73:480-8.

40. Jaar BG, Plantinga LC, Crews DC, Fink NE, Hebah N, Coresh J, et al. Timing, causes, predictors and prognosis of switching from peritoneal dialysis to hemodialysis: a prospective study. BMC Nephrol 2009; 10:3.

41. Batt J, Linton K, Bennett PN. Home hemodialysis: a successful option for obese and bariatric people with end-stage kidney disease. Hemodial Int 2012; 16(Suppl 1):S26-31.

42. United States, Department of Health and Human Services, National Institutes of Health, National Institute of Diabetes and Digestive and Kidney Disease, US Renal Data System (USRDS). Annual Data Report: Atlas of Chronic Kidney Disease and End-Stage Renal Disease in the United States. Bethesda, MD: USRDS; 2013.

This single copy is for your personal, non-commercial use only. For permission to reprint multiple copies or to order presentation-ready copies for distribution, contact Multimed Inc. at marketing@multi-med.com 